\title{
Evolving Molecular Methods for Detection of Mutations
}

\section{Mohammad Al-Haggar*}

Department of Pediatrics, Genetics Unit, Faculty of Medicine, Mansoura University, 35516 Mansoura, Egypt

Mutations are permanent changes in DNA which may be either germ line if present in a gamete involved in fertilization leading to conception of an individual in whom it is present in every cell, or somatic if occur in only a portion of the body cells. Completion of the map of human genetic code through the Human Genome Project 2003 yielded it is possible to understand the basic molecular defect of most genetic diseases and opened the gate for comprehension of many phenotype-genotype correlates. Since that time, the molecular methods for detection of mutation are evolving from the old basic tedious and time consuming experiments to rapid throughput works that could be completed in a narrow spaced laboratory.

There are many procedures encountered in mutation analysis, some are used together in succession, moreover many conventional methods are subjected for modifications every now and then. Of these procedures and its evolutionary techniques, we could mention the following:

- Southern blotting

- Restriction fragment length polymorphism (RFLP)

- PCR/RFLP (size analysis of PCR products)

- Amplification-refractory mutation system (ARMS) PCR

- Heteroduplex migration analysis

- Single- strand conformational polymorphism (SSCP) analysis

- Denaturating gradient gel electrophoresis (DGGE)

- Denaturating high performance liquid chromatography (DHPLC)

- Conformation-sensitive capillary electrophoresis (CSCE)

- Oligonucleotide ligation assay (OLA)

- Real-time PCR

- DNA microarrays (DNA chips)

- High-resolution melt curve analysis (HRM)

Direct determination of DNA sequences has been made easy using the new generations of automated sequencing machines. DNA amplification using fluorescent nucleotides is the basis of most equipments, then products are subjected to electrophoresis and the fluorescence signal during its moves through a window is generated that will be converted into an electronic signal analyzed by a computer to produce a color graph that signify each nucleotide [1]

Southern blotting, named after its inventor, Edward Southern, is a procedure used to detect DNA fragments of the DNA stretch digested by restriction enzymes [2]. After a DNA stretch being digested by a specific enzyme into fragments called restriction fragment length polymorphism (RFLP) that differ in size and molecular weight based on the recognition sites of these enzymes, fragments will then be separated using agarose gel electrophoresis. Denaturation of DNA fragments in the gel is accomplished by soaking it in an alkaline solution to allow for their efficient transfer to a nylon membrane, detection of the fixed DNA fragments on membrane is achieved by many methods (radio-labeled and biotin labeled) using complementary probes through a technique defined as Hybridization. Variations in the molecular size of DNA fragments caused by variations in positions of the restriction sites as a result of different forms of mutation yield RFLP. It has to be stressed that Hybridization had been used in many modifications for the indirect determination of DNA sequences using the complementary probes [3].

Amplification of DNA stretch through PCR using labeled nucleotides followed by study of the restriction fragments, PCR/RFLP (size analysis of PCR products), could make recognition of mutants very simple and easy especially if present in a heterozygous form. After PCR, the products are digested with one or more restriction enzymes and analyzed by electrophoresis [4].

An allele specific amplification had been invented for the target detection of common mutations through a type of PCR called Amplification Refractory Mutation System (ARMS) analysis. It consists of two complementary reactions and utilizes three primers; one is constant and complementary to template in both reactions, the other primers differ at their 3 ' terminal residues and are specific to either the wild or mutant allele; in homozygous mutant or homozygous wild, amplification will occur in only one tube, however in heterozygous, amplification will be seen in both tubes [5]. This method had been applied for diagnosis of many common genetic diseases in our region like the common mutations of $\beta$-thalassemia in Mediterranean coast [6].

Differential migration of DNA heteroduplexes compared to homoduplexes run on a polyacrylamide gel had been done though a technique called Heteroduplex migration analysis. Heteroduplexes made up of two mismatched single strands usually show an abnormal mobility on a polyacrylamide gel; PCR products from a suspected carrier are denaturated and then allowed to reanneal to a normal PCR product so that normal and mutant single strands form heteroduplexes that can be easily detected on the gel [7]. It is useful for detection of carriers of X-linked recessive disorders.

Screening for the presence or absence of mutation in an amplified exon can be accomplished using the Single-Strand Conformational Polymorphism (SSCP) analysis. It is based on the fact that single DNA strand folds to form a complex three-dimensional structure maintained by intra-molecular bonds; about $80 \%$ of mutations alter the pattern of folding and consequently alters the electrophoretic mobility of DNA strand on the gel. Differential mobility between test and control DNA samples suggests a mutation in an amplified exon that can then be sequenced to determine the exact change $[1,8]$.

Denaturating gradient gel electrophoresis (DGGE) is a more demanding procedure than SSCP and heteroduplex migration analyses with a higher sensitivity (over 90\%) for identifying mutations especially

*Corresponding author: Mohammad Al-Haggar, Department of Pediatrics, Genetics Unit, Faculty of Medicine, Mansoura University, 35516 Mansoura, Egypt, Tel:'2011117 15 350; Fax: 2050223 4092; E-mail: m.alhaggar@yahoo.co.uk

Received December 15, 2012; Accepted December 19, 2012; Published December 29, 2012

Citation: Al-Haggar M (2013) Evolving Molecular Methods for Detection of Mutations. Gene Technology 2: e104. doi: 10.4172/2329-6682.1000e104

Copyright: (c) $2013 \mathrm{Al}$-Haggar M. This is an open-access article distributed under the terms of the Creative Commons Attribution License, which permits unrestricted use, distribution, and reproduction in any medium, provided the original author and source are credited. 
in survey studies. Its basic principle relies on the fact that normal and mutant sequences will show different band patterns on a gel. The PCR products are run on a special denaturing gradient gel that contains increasing concentrations of a denaturing chemical such as urea. Double strand DNA denatures forming a single strand that stops at different points if the product has come from a heterozygote. Once again, the relevant exon can then be sequenced to identify the specific underlying mutation $[1,9]$.

Denaturating high performance liquid chromatography (DHPLC), in similar ways to DGGE, detects heteroduplexes owing to their abnormal denaturing profiles. It is based on the differential separation of mismatched heteroduplexes which form after the reannealing of normal and mutant DNA strands. PCR products are injected in a column containing an increasing gradient of mobile phase (acetonitrite) required to elute each homo- or heteroduplex. DHPLC is an extremely sensitive method for detecting base substitutions, small deletions and insertions [10].

Conformation-sensitive capillary electrophoresis (CSCE) is a faster technique that achieves a higher throughput than DHPLC in detection of the heteroduplexes using fluorescence technology $[10,11]$.

Through Oligonucleotide Ligation Assay (OLA), a pair of oligonucleotides is designed to anneal to adjacent sequences within a PCR product. If they are perfectly hybridized, they can be joined by a DNA ligase. Oligonucleotides complementary to the normal and mutant sequences are differentially labeled and the products are identified by a computer software. Quantitative PCR using Real-time has many applications in biotechnology, there are multiple hardware platforms for real-time PCR, and fast versions that can complete a PCR reaction in less than 30 minutes. $[10,12]$.

Nucleotide enumeration nowadays is fully automated through a hardware platform; however up to date revision on gene atlas is sometimes necessary in some genetic disorders as the discovery of new exons in a gene should make changes in exon re-numbering. This phenomenon is actually very frequent especially in splicing mutations; about $15 \%$ of 11,000 splicing mutations when recently and manually revisited at HGMD should have their exons renumbered. This is due to the fact that the structure of many genes has 'changed' since the initial reports of mutations [13].

DNA microarrays (DNA chips) consist of small devices (coated glass microscope slides) onto which large numbers of different DNA sequences have been positioned in the form of a grid. In one type of microarray, tiny amounts of DNA are spotted onto the coated slide by an automated robot. In another type, the different DNA sequences consist of oligonucleotides produced by in situ synthesis (gene chip). These techniques are capable of detecting both microscopic and submicroscopic copy number changes for the whole genome in a single assay. There are two major microarray platforms for genomic DNA profiling; comparative genomic hybridization (CGH) arrays and genotyping arrays. Regardless of the technical differences in chip manufacturing and probe types used with these platforms, they share the same principle and rely on the specific hybridization of target and probe sequences. CGH arrays use a two-color scheme. The method infers the copy number changes in a test sample by comparing it with a reference sample. Genotyping arrays, on the other hand, do not use a control sample; rather, they use the intensity of the hybridization signal to indicate the relative DNA copy number. In addition, genotyping arrays provide information on single-nucleotide polymorphism (SNP) genotypes [14].

High-resolution melt curve analysis (HRM) is a technique employing a new class of fluorescent dyes that intercalates with double strand DNA. The intercalating dye is incorporated in a PCR reaction, the PCR products are then heated to separate the two strands. Fluorescence levels decrease as the DNA strands dissociate and this melting profile depends on the PCR product size and sequence. HRM appears to be very sensitive. The detection capability of HRM is largely determined by fragment length, sequence composition, mutation identity, PCR quality and the analytical equipment [15].

To sum up, basic molecular techniques are subjected to modifications and optimizations based on the studied genetic disease, mutation type and troubleshoots in laboratory circumstance. However the essence of laboratory technique remains fixed in the frame of its original description e.g. amplification, digestion, differential separation, labeling and hybridization.

\section{References}

1. Young I (2010) Gene structure and function. In: Medical Genetics. (2ndedn), Oxford University Press, New York.

2. Southern EM (1975) Detection of specific sequences among DNA fragments separated by gel electrophoresis. J Mol Biol 98: 503-508.

3. Maniatis T, Fritsch E, Sambrook J (1982) Molecular cloning: a laboratory manual Textbook. Cold Spring Harbor Laboratory.

4. Mitra RD, Butty VL, Shendure J, Williams BR, Housman DE, et al. (2003) Digital genotyping and haplotyping with polymerase colonies. Proc Natl Acad Sci USA 100: 5926-5931.

5. Newton CR, Graham A, Heptinstall LE, Powell SJ, Summers C, et al. (1989) Analysis of any point mutation in DNA. The amplification refractory mutation system (ARMS). Nucleic Acids Res 17: 2503-2516.

6. Settin AA, Al-Haggar MM, Neamatallah M, Al- Said AM, Hafez MM (2006) Detection of Beta-thalassemia Mutations Using Primer-Specific Amplification Compared to Reversed Dot Blot Hybridization Technique in Egyptian Cases. Haema9: 401-409.

7. Williams IJ, Goodeve AC (2002) Conformation-sensitive gel electrophoresis PCR Mutation Detection Protocol 187: 137-150.

8. Gupta V, Arora R, Ranjan A, Bairwa NK, Malhotra DK, et al. (2005) Gel-based nonradioactive single-strand conformational polymorphism and mutation detection: limitations and solutions. Methods Mol Biol 291: 247-261.

9. Tomaiuolo R, Spina M, Castaldo G (2003) Molecular diagnosis of cystic fibrosis: comparison of four analytical procedures. Clin Chem Lab Med 41: 26-32.

10. Turnpenny P, Ellard S (2007) DNA technology and applications. In: Emery's Elements of Medical Genetics.(13thedn), Churchill Livingstone Elsevier's Press, Philadelphia.

11. Shin GW, Jung SH, Yim SH, Chung B, Jung GY, et al. (2012) Stuffer-free multiplex ligation-dependent probe amplification based on conformationsensitive capillary electrophoresis: a novel technology for robust multiplex determination of copy number variation. Electrophoresis 33: 3052-3061.

12. Krawczyk B, Leibner-Ciszak J, Stojowska K, Kur J (2011) The new LM-PCR/ shifter method for the genotyping of microorganisms based on the use of a class IIS restriction enzyme and ligation mediated PCR. J Microbiol Biotechnol 21: 1336-1344.

13. Al-Haggar M, Sakamoto O, Shaltout A, Al-Hawari A, Wahba Y, et al. (2012) Mutation analysis of the GLUT2 gene in three unrelated Egyptian families with Fanconi-Bickel syndrome: revisited gene atlas for renumbering. Clin Exp Nephrol 16: 604-610.

14. Shen Y, Wu BL (2009) Microarray-based genomic DNA profiling technologies in clinical molecular diagnostics. Clin Chem 55: 659-669.

15. Milbury CA, Li J, Makrigiorgos GM (2009) COLD-PCR-Enhanced highresolution melting enables rapid and selective identification of low-level unknown mutations. Clin Chem 55: 2130-2143. 